\title{
Accessory mental foramen: a rare anatomical finding
}

\author{
Gagan Thakur, ${ }^{1}$ Shaji Thomas, ${ }^{1}$ Sumeeth Cyriac Thayil,, ${ }^{1}$ Preeti P Nair ${ }^{2}$ \\ 'Department of Oral \& Maxillofacial Surgery, People's College of Dental Sciences and Research Centre, Bhanpur, Bhopal, Madhya Pradesh, India; \\ ${ }^{2}$ Department of Oral Medicine \& Radiology, People's College of Dental Sciences and Research Centre, Bhanpur, Bhopal, Madhya Pradesh, India
}

Correspondence to Preeti P Nair, shajihoss@gmail.com

\section{Summary}

Accessory mental foramen (AMF) is a rare anatomical variation with a prevalence ranging from 1.4 to $10 \%$. Even so, in order to avoid neurovascular complications, particular attention should be paid to the possible occurrence of one or more AMF during surgical procedures involving the mandible. Careful surgical dissection should be performed in the region so that the presence of AMF can be detected and the occurrence of a neurosensory disturbance or haemorrhage can be avoided. Although this anatomical variation is rare, it should be kept in mind that an AMF may exist. Trigeminal neuralgia was diagnosed. On the basis of diagnostic test results, peripheral neurectomy of mental nerve was planned. Failure to do neurectomy of mental nerve branch in the reported case, coming out from AMF, would have resulted in recurrence of pain and eventually failure of the procedure.

\section{BACKGROUND}

Multiple mental foramen is a rare anatomical finding, which, if not recognised, can lead to unexpected surgical outcome.

\section{CASE PRESENTATION}

\section{Introduction}

The mental foramen is located on the anterolateral aspect of the mandible, 13-15 mm superior to the inferior border of the mandibular body. The direction of the opening of the mental foramen is outward and upward in a posterior orientation. ${ }^{1}$ The mental foramen is most usually single in human beings; when it is double or multiple, the additional foramen is termed accessory foramen. An AMF is reported to be rare, with a prevalence ranging from 1.4 to $10 \%{ }^{2}$

\section{Case report}

A male patient aged 40 years was referred to the Department of Oral and Maxillofacial Surgery, People's College of Dental Sciences and Research Centre with symptoms of paroxysmal pain on right side of the face since 2 years.

On examination, pain was sudden in onset. A severe, electric shock-like, stabbing pain was typically felt on right side of the face. The attacks of pain, which generally lasted several seconds, were recorded thrice in an entire day. Pain was localised to right side of the face, lower lip, and corner of mouth and over the inferior border of the mandible. Contact to lower lip, corner of mouth and lower border of mandible resulted in precipitation of pain. Diagnostic block was given for right mental nerve block using 3.5 cc lignocaine hydrochloride, after which the patient was free of

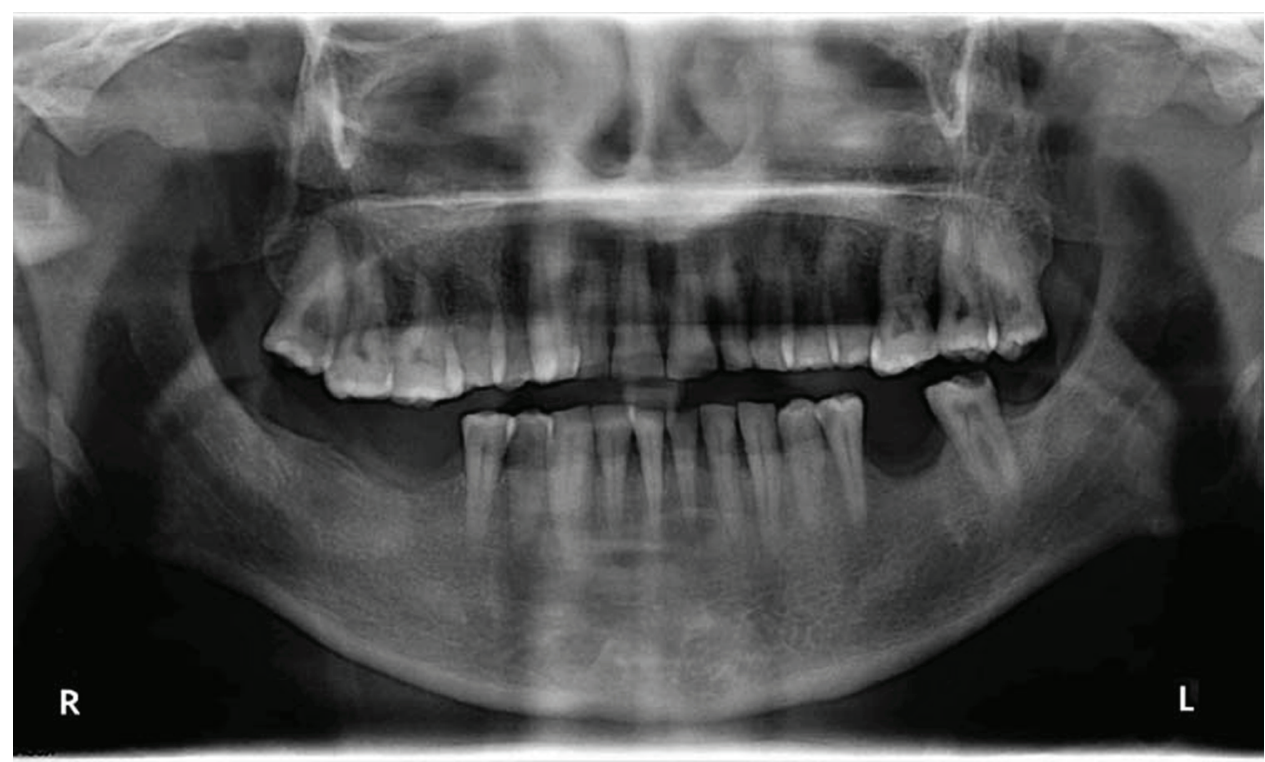

Figure 1 Panaromic view of mandible. 


\section{BMJ Case Reports}

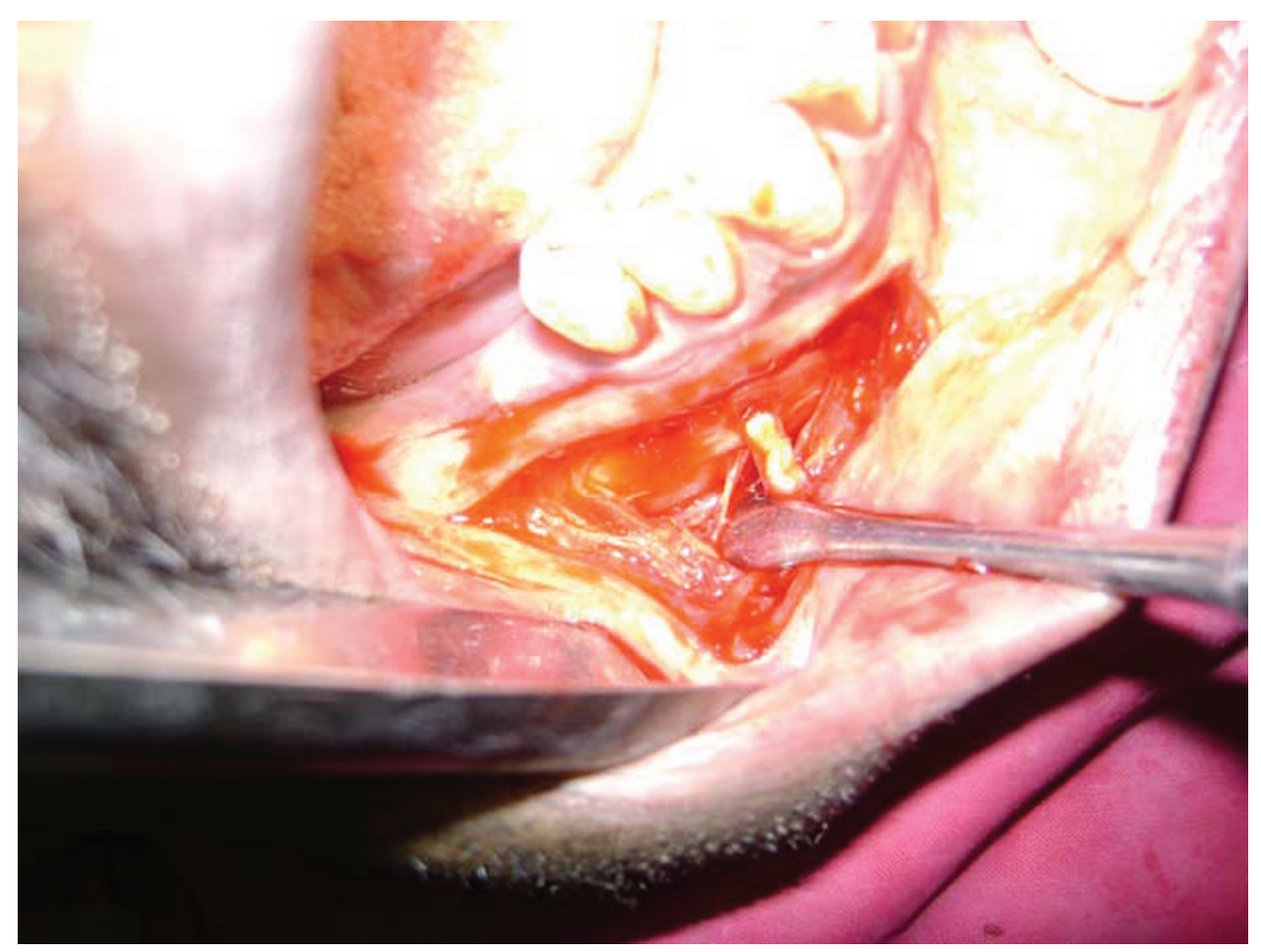

Figure 2 Accessory mental nerve.

symptoms. Examination of oral cavity, temporomandibular joint and paranasal sinuses was otherwise unremarkable.

Patient was diagnosed as having trigeminal neuralgia. Medical treatment was planned; patient was prescribed tab tegretol $200 \mathrm{mg}$ three times a day. Patient did not respond to this therapy after even increasing the dose to $600 \mathrm{mg}$ three times a day.

Patient was advised CT scan for further evaluation, which he refused.

Peripheral neurectomy of right mental nerve of mandibular division procedure was planned and performed. Following standard vestibular incision, mental foramen and $\mathrm{AMF}$ were discovered during subperiosteal dissection. AMF was observed $5 \mathrm{~mm}$ inferior and posterior to existing mental foramen with a branch of mental nerve coming out of it. Peripheral segment including accessory and main branch of mental nerve was dissected out and cut. Both the foramen were packed by bone wax (figures 1-4).

Patient was followed up over a period of 1 year; he had no fresh complaints of pain.

\section{Conclusion}

Accessory mental foramina have been reported to be detected by macroscopic investigations on dry skulls, investigations with plane radiography, periapical radiography and CT. Unbiased radiological interpretation of an AMF is possible only on CT images since the disadvantages of low-image quality, low magnification and distortion on the panoramic and periapical radiographs are of concern. ${ }^{3}$ If the mental foramen cannot be clearly identified on panoramic radiographs under ordinary exposure and viewing conditions, a $3 \mathrm{D}-\mathrm{CT}$ should be utilised to determine the extent and location of the mental foramen prior to surgical procedures. However, if only a panoramic radiograph instead of a CT scan can be obtained, in order to improve visualisation of the mandibular canal, the patient's head should be tilted $5^{\circ}$ downward with reference to the Frankfort horizontal reference bar of the machine. ${ }^{4}$

Failure to do neurectomy of mental nerve branch in the reported case, coming out from AMF, would have resulted in recurrence of pain and eventually failure of the procedure.

Utmost care to the AMF and nerve is essential during dental implant surgery and any surgical procedure involving the mandibular molar and premolar region. This care may reduce the rate of haemorrhage and paresis in the mental region, lower lip and gingiva of the ipsilateral side and recurrence of neuralgic pain in this case.

The probability of the existence of an AMF should be kept in mind.

\section{INVESTIGATIONS}

Routine blood investigations were done for minor oral surgery.

\section{TREATMENT}

Mental nerve peripheral neurectomy was performed under local anaesthesia.

\section{OUTCOME AND FOLLOW-UP}

The patient was relieved of the complaint and recovered well.

\section{DISCUSSION}

The mental foramen is incomplete until the 12th gestational week, when the mental nerve separates into several 


\section{BMJ Case Reports}

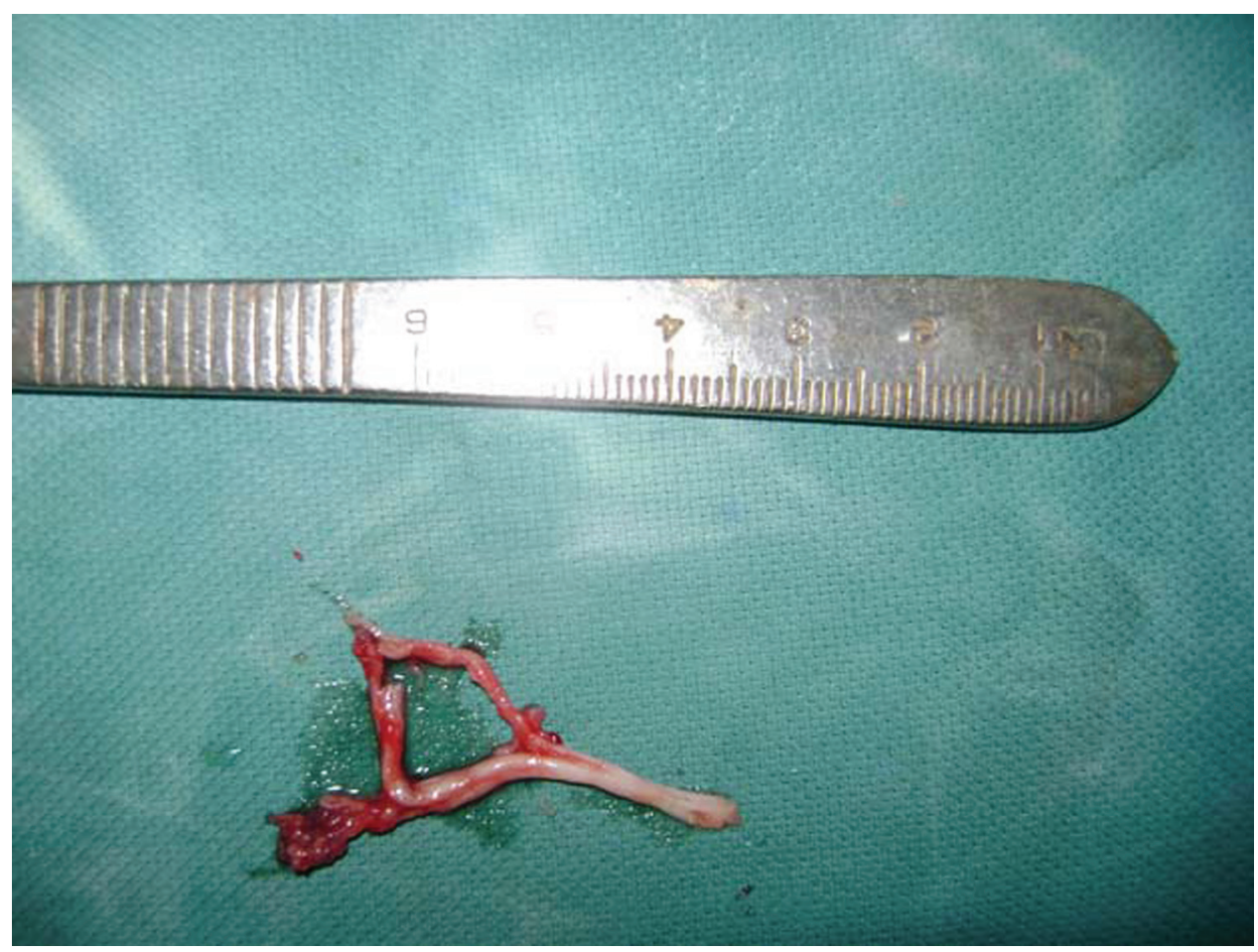

Figure 3 Sectioned mental nerve showing accessory mental nerve segment.

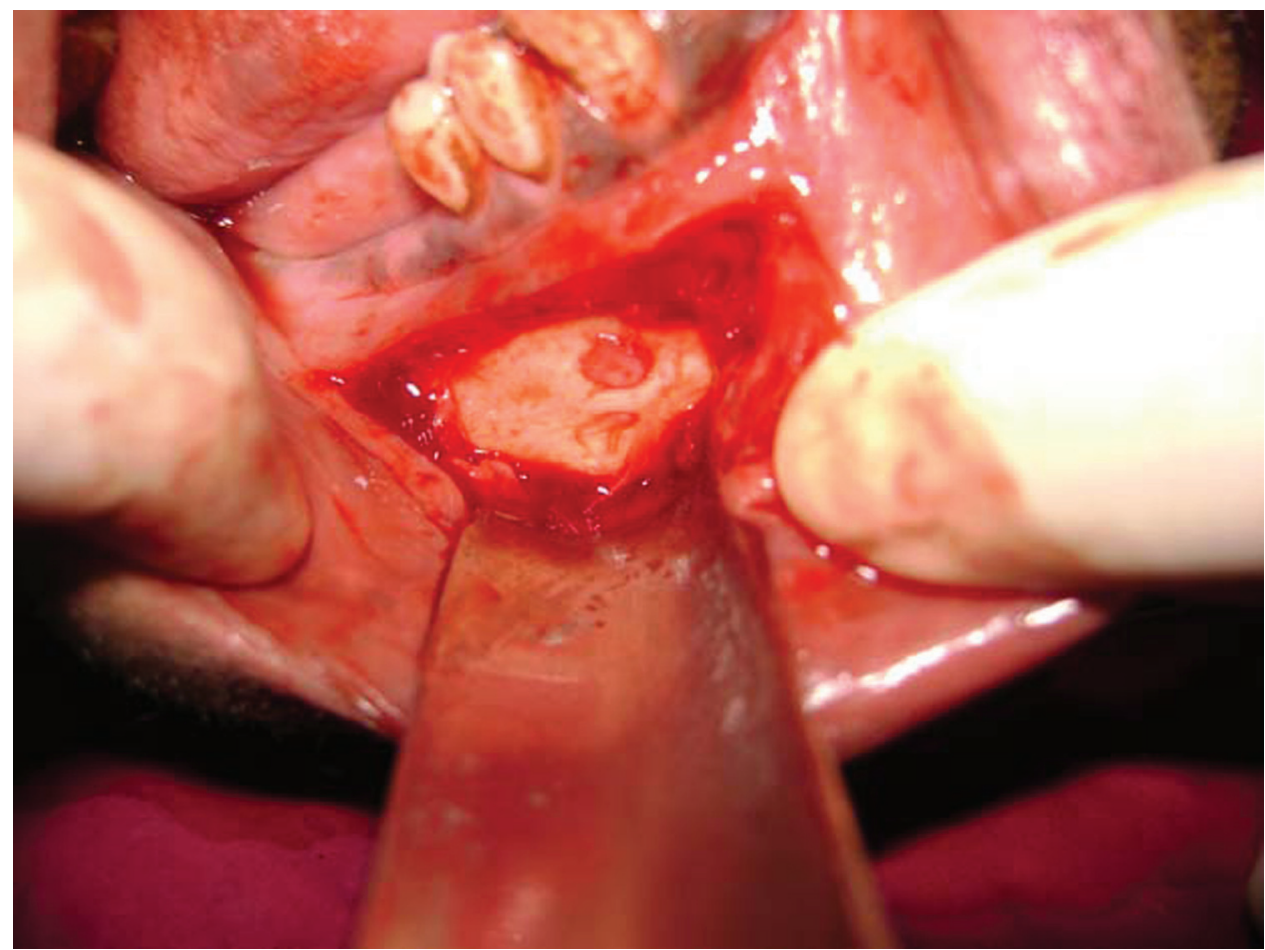

Figure 4 Mental and accessory mental foramen.

fasciculi at that site. It has been suggested that separation of the mental nerve earlier than the formation of the mental foramen could be a reason for the formation of the AMF. ${ }^{5}$

The incidence of AMF varies between ethnic groups, and is reported as follows: $2.6 \%$ in French; $1.4 \%$ in American
Whites; $5.7 \%$ in American Blacks; 3.3\% in Greeks; $1.5 \%$ in Russians; $3.0 \%$ in Hungarians; $9.7 \%$ in Melanesians and $3.6 \%$ in Egyptians. ${ }^{6}$ Studies performed in a Japanese population showed that AMF is less rare, with a prevalence ranging from 6.7 to $12.5 \%$ in Japan. ${ }^{7}$ In a study, unilateral 


\section{BMJ Case Reports}

\section{Learning points}

- Failure to do neurectomy of mental nerve branch in the reported case, coming out from AMF, would have resulted in recurrence of pain and eventually failure of the procedure.

- Proper radiographic evaluation is to be performed before commencing peripheral neurectomies to rule out the presence of AMFs.

- During routine surgeries involving the chin region, the surgeon has to exercise utmost care to avoid damage to accessory nerves.

AMF was found in 45 dry mandibles $(2.22 \%) .{ }^{8}$ These reports reveal that non-Caucasians may have a higher incidence of AMF than Caucasians.

Previous studies reported no gender differences. ${ }^{7} 8$ This case report is on a male patient.

In the case reported here, the foramina were located under the second premolar. This finding is consistent with the findings of a previous study in which the highest percentage $(42.3 \%)$ of mental foramen were found under the second premolar. ${ }^{8}$

Absence of mental foramen has also been reported in 3 cases out of 2870 sides of 1435 dry skulls. ${ }^{9}$ Published reports on the absence of mental foramen, apart from the two cases cited by de Freitas et al, ${ }^{9}$ have not been found.

Second Department of Oral Anatomy, Fukuoka Dental College, examined the range of the AMF and its accessory mental nerve in three Japanese cadavers. The diameters of the AMF were relatively small: $0.74,0.80$ and $0.89 \mathrm{~mm}$. The distances between the mental foramen and AMF were $0.67,2.1$ and $5.74 \mathrm{~mm}$. The distribution of the accessory mental nerve was different in the three cases. These nerves communicated with the branches of the facial and buccal nerves. $^{7}$

Reports of neurosensory disturbances during surgical procedures involving the mandible are not rare; for instance, neurosensory disturbances are reported to range up to $12 \%$ in genioplasty. ${ }^{3} 10$

Surgeons should always dissect carefully to avoid neurovascular complications during implant placement, regional anaesthesia, surgical correction of jaw deformities and periapical surgery.

\section{Competing interests None.}

Patient consent Obtained.

\section{REFERENCES}

1. Haghanifar $\mathbf{S}$, Rokouei M. Radiographic evaluation of the mental foramen in a selected Iranian population. Indian J Dent Res 2009;20:150-2.

2. Igarashi C, Kobayashi K, Yamamoto A, et al. Double mental foramina of the mandible on computed tomography images: a case report. Oral Radiol 2004;20:68-71.

3. Balcioglu HA, Kocaelli H. Accessory mental foramen. North Am J Med Sci 2009;1:314-15.

4. Dharmar S. Locating the mandibular canal in panoramic radiographs. Int J Oral Maxillofac Implants 1997;12:113-17.

5. Naitoh M, Hiraiwa $\mathrm{Y}$, Aimiya $\mathrm{H}$, et al. Accessory mental foramen assessment using cone-beam computed tomography. Oral Surg Oral Med Oral Pathol Oral Radiol Endod 2009:107:289-94.

6. Sawyer DR, Kiely ML, Pyle MA. The frequency of accessory mental foramina in four ethnic groups. Arch Oral Biol 1998;43:417-20.

7. Toh H, Kodama J, Yanagisako M, et al. Anatomical study of the accessory mental foramen and the distribution of its nerve. Okajimas Folia Anat Jpn 1992;69:85-8.

8. Kokten G, Buyukanten M, Balcioglu HA. Foramen mentalenin cap ve lokalizasyonunun kuru kemik ve panoramik radyografilerde. Istanbul Univ Dishekim Fak Derg 2004;38:65-71.

9. de Freitas V, Madeira MC, Toledo Filho JL, et al. Absence of the mental foramen in dry human mandibles. Acta Anat (Basel) 1979;104:353-5.

10. Hwang $\mathbf{K}$, Lee WJ, Song YB, et al. Vulnerability of the inferior alveolar nerve and mental nerve during genioplasty: an anatomic study. J Craniofac Surg 2005:16:10-14.

This pdf has been created automatically from the final edited text and images.

Copyright 2011 BMJ Publishing Group. All rights reserved. For permission to reuse any of this content visit http://group.bmj.com/group/rights-licensing/permissions.

BMJ Case Report Fellows may re-use this article for personal use and teaching without any further permission.

Please cite this article as follows (you will need to access the article online to obtain the date of publication).

Thakur G, Thomas S, Thayil SC, Nair PP. Accessory mental foramen: a rare anatomical finding. BMJ Case Reports 2011;10.1136/bcr.09.2010.3326, date of publication

Become a Fellow of BMJ Case Reports today and you can:

- Submit as many cases as you like

- Enjoy fast sympathetic peer review and rapid publication of accepted articles

- Access all the published articles

- Re-use any of the published material for personal use and teaching without further permission

For information on Institutional Fellowships contact consortiasales@bmjgroup.com

Visit casereports.bmj.com for more articles like this and to become a Fellow 